\title{
Polymeric Hydrogel Nanocapsules: A Thermo and pH Dual-responsive Carrier for Sustained Drug Release
}

Jingya Nan ${ }^{1}$, Ying Chen ${ }^{1,2, *}$, Rutian $\mathrm{Li}^{3}$, Jifu Wang ${ }^{1,2}$, Meihong $\mathrm{Liu}^{1}$, Chunpeng Wang ${ }^{1, *}, \quad$ Fuxiang $\mathrm{Chu}^{4}$

(Received 30 October 2013; accepted 11 March 2014; published online July 1, 2014)

\begin{abstract}
Hydrogel capsules show attractive prospects in drug delivery recently because of high drug loading and sustained release behavior. In this study we reported a simple and convenient route to fabricate poly (acrylic acid)-poly (N-isopropylacrylamide) (PAA-PNIPAm) hydrogel capsules by using hydroxypropylcellulose-poly (acrylic acid) (HPC-PAA) complexes as the templates. The capsules showed a high drug loading ( $\sim 280 \%$ to the weight of capsules) for Doxorubicin hydrochloride. The release of drug from the capsules was responsive to the temperature and $\mathrm{pH}$ of the surroundings, showing a low-rate but sustained release behavior favorable for low-toxic and long-term therapy. Together with the convenient preparation, high drug loading, dual responsivity as well as the sustained release feature, it is implied that this polymeric hydrogel capsule might be a promising candidate for new drug carriers.
\end{abstract}

Keywords: Hydrogel capsules; Sustained release; High drug loading; Dual responsivity

Citation: Jingya Nan, Ying Chen, Rutian Li, Jifu Wang, Meihong Liu, Chunpeng Wang and Fuxiang Chu, "Polymeric Hydrogel Nanocapsules: A Thermo and pH Dual-responsive Carrier for Sustained Drug Release", Nano-Micro Lett. 6(3), 200-208 (2014). http://dx.doi.org/10.5101/nml140022a

\section{Introduction}

In the past few decades, polymer-based drug vehicles have attracted significant interests in the development of drug delivery system mainly owing to the tailorability, easy-functionalization and biocompatibility of polymers [1-5]. Polymeric drug vehicles such as nanoparticles, micelles, nanogels, micro/nano capsules are very advantageous in the control of drug distribution in the living organism, prolonging the biological activity of drugs, improving the therapeutic effect and reducing the administration frequency [6-10]. It is revealed that capsule-like drug carriers could easily realize high drug payload and achieve a better sustained release behavior due to their larger inner cavities [11-14], hence many efforts have been devoted to the synthesis of polymeric capsules. Layer-by-Layer (LbL) assembly is a widely used route to the preparation of polymeric capsules with well-defined chemical and structural properties, which potentially afford a large degree of control over functional properties of polyelectrolyte containers, such as their permeability to low molecular weight compounds or macromolecules $[15,16]$. For example, Möhwald's group has reported a series of $\mathrm{pH}$-sensitive LbL capsules, of which the wall could be triggered by $\mathrm{pH}$ or ionic strength to switch on and

\footnotetext{
${ }^{1}$ Institute of Chemical Industry of Forest Products, Chinese Academy of Forestry; Key Laboratory of Biomass Energy and Material, Jiangsu Province; National Engineering Laboratory for Biomass Chemical Utilization; Key and Open Laboratory on Forest Chemical Engineering, SFA, Nanjing 210042, China

${ }^{2}$ Institute of New Technology, Chinese Academy of Forestry, Beijing 100091, China

${ }^{3}$ The Comprehensive Cancer Center, Drum-Tower Hospital of Nanjing University and Clinical Cancer Institute of Nanjing University, Nanjing 210008, China

${ }^{4}$ Chinese Academy of Forestry, Beijing 100091, China

*Corresponding author. E-mail: yingchencaf@gmail.com, wangcpg@163.com
} 
off between 'open' and 'closed' state for guest macromolecules [17-19]. Caruso group has recently found that when disulfide links are used for cross-linking of the hydrogel capsules system, a disulfide exchange reagent can be used to trigger release of a model drug [20-22]. However, there are some intrinsic shortcomings in the LbL approach, e.g., difficult to achieve high yield owing to the multistep preparation, absent of structural robustness of the shell upon template removal, and great challenge to refill the hollow interior with functional substance. As a result, a convenient fabrication procedure to the capsules with satisfactory loading capacity and expected stimuli-responsive behavior is highly desired in terms of practical applications of the capsules in biomedical area.

Recently various approaches have been developed for the massive preparation of polymeric capsules [23-25], and template method is especially attractive by precipitating polymers on the surface of granular templates or removing selectively the core of the templates [26-28]. Kozlovskaya group developed a series of weak polyacid based cross-linked capsules by hydrogen-bonded selfassembly as drug carriers [29-31]. In our previous work, various poly (acrylic acid) (PAA)-based micro/nanogels were prepared by using the precipitation polymerization method [32-34]. The obtained nanogels showed a high drug loading capacity and a sustained release feature for water-soluble drug molecules. In this study, in order to enlarge the inner space of the PAA-based particles and gain further high drug loading capacity, we optimized the synthetic strategy in which HPC-PAA was performed as templates followed by the surface polymerization of N-isopropylacrylamide (NIPAm) and the removal of HPC cores, leading to the PAA-PNIPAm hydrogel capsules finally. These capsules exhibit a new high drug loading of $\sim 280 \%$ for anticancer drug Doxorubicin hydrochloride (Dox). The in vitro release and anticancer effect on the human intestine cancer cell LoVo show a responsive behavior upon the change in temperature and $\mathrm{pH}$ value of the surroundings. In combination of the convenient preparation, high drug loading, dual responsivity as well as the sustained release feature, this polymeric hydrogel capsules show potential application in drug controlled-release system. Importantly, the multiple carboxylic groups on the capsules surface allow functionalization on the capsules with a variety of macromolecules at mild conditions, such as targeting group. This makes the capsules ideal candidates for the target therapy.

\section{Experimental Section}

\section{Materials}

Hydroxypropylcellulose (HPC, $\mathrm{M}_{\mathrm{w}}=100,000$ Da), $\mathrm{N}, \mathrm{N}$-Methylenebisacrylamide (MBAAm) and N- isopropylacrylamide (NIPAm) were purchased from Acros Chemical Company. Sodium dodecyl sulphate (SDS) and Acrylic acid (AA) were purchased from Shanghai Guanghua Chemical Company. Doxorubicin hydrochloride (Dox) was purchased from Beijing Huafeng United Technology Company. All the other reagents were of analytical grade and used without further purification. Distilled water was used for all polymerization and treatment processes. Human intestinal cancer LoVo cells were obtained from Shanghai Institute of Cell Biology (Shanghai, China).

\section{Preparation of the HPC-PAA template particles}

The HPC-PAA template particles were synthesized by direct polymerization of AA in HPC aqueous solution. In a typical run, $0.20 \mathrm{~g}$ of HPC was dissolved in 35 $\mathrm{mL}$ aqueous solution containing $0.20 \mathrm{~g}$ of AA. The solution was stirred at room temperature until it became clear. Then $500 \mu \mathrm{L}$ of ascorbic acid $(0.10 \mathrm{~mol} / \mathrm{L})$ and hydrogen peroxide $\left(\mathrm{H}_{2} \mathrm{O}_{2}\right)(0.10 \mathrm{~mol} / \mathrm{L})$ solution were separately added into the above solution to initiate the polymerization of $\mathrm{AA}$ at $35^{\circ} \mathrm{C}$ under the protection of nitrogen gas. When the polymerization of AA reached a certain level, opalescent suspension occurred, indicating the formation of HPC-PAA template particles. The reaction was allowed to proceed at $35^{\circ} \mathrm{C}$ for $1 \mathrm{~h}$.

\section{Preparation of PAA-PNIPAm hydrogel capsules}

The PAA-PNIPAm hydrogel capsules were prepared as follows: $15 \mathrm{~mL}$ aqueous solution containing $0.20 \mathrm{~g}$ of NIPAm, $0.15 \mathrm{~g}$ of MBAAm and $0.05 \mathrm{~g}$ of SDS was added into the HPC-PAA template particles suspension. Then the polymerization of NIPAm was carried out at $35{ }^{\circ} \mathrm{C}$ under a nitrogen stream and magnetic stirring. The reaction kept on for another $2 \mathrm{~h}$ before being cooled down to the room temperature, resulting in the HPC-PAA-PNIPAm complex particles. Appropriate amount of HPC-PAA-PNIPAm particles were redispersed in water and the $\mathrm{pH}$ of the suspension was adjusted to 8.0 using $0.1 \mathrm{~mol} / \mathrm{L}$ of $\mathrm{NaOH}$ [34]. The PAA-PNIPAm hydrogel capsules were finally obtained after several centrifuging/washing cycles with water.

\section{Preparation of Dox-loaded PAA-PNIPAm hy- drogel capsules}

The Dox-loaded PAA-PNIPAm hydrogel capsules were prepared by an incubation method at $\mathrm{pH}=7.0$. A certain content of PAA-PNIPAm hydrogel capsules were mixed with the Dox solution of a predetermined concentration $(0.4,0.8,1.2,1.6,2.0 \mathrm{mg} / \mathrm{mL})$ at room temperature. The mixed solution was incubated at $37^{\circ} \mathrm{C}$ for $12 \mathrm{~h}$ to allow Dox entrapment in the hydrogel capsules to reach an isothermal equilibrium. The drug loading efficiency and loading capacity of PAA- 
PNIPAm hydrogel capsules were determined by separating capsules from the aqueous medium containing free Dox via centrifugation (12,000 rpm, $20 \mathrm{~min})$. The amount of free Dox was measured on a UV-vis spectrometer at $495 \mathrm{~nm}$. The loading efficiency (LE) and loading capacity (LC) were calculated with the following equations:

LE (\%) = weight of drug entrapped in hydrogel capsules/ weight of drug fedinitially*100\%

LC $(\%)=$ weight of drug entrapped in hydrogel capsules/ weight of dry hydrogel capsules*100\%

\section{In vitro release}

The Dox release from the hydrogel capsules was evaluated by the dialysis method. Dox-loaded PAAPNIPAm hydrogel capsules were placed in a dialysis bag $(\mathrm{MWCO}=14,000 \mathrm{Da})$ and dialyzed against the PBS solution with predetermined $\mathrm{pH}$ value $(\mathrm{pH}=4.0$, 5.0 and 7.4$)$ at particular temperatures $(\mathrm{T}=25,30$ and $37^{\circ} \mathrm{C}$ ), respectively. The released drug outside the dialysis bag was sampled at selected time intervals and measured with a UV-vis spectrometer.

\section{In vitro cytotoxicity}

The cell viability for free Dox, empty and Doxloaded PAA-PNIPAm hydrogel capsules on the LoVo cell lines were evaluated by MTT assay. LoVo cells (5000 cells/well) were cultured in RPMI 1640 containing $10 \%$ fetal bovine serum in a 96 -well multiplate. Afterwards, the cells were exposed to free Dox, empty and Dox-loaded PAA-PNIPAm hydrogel capsules respectively for $48 \mathrm{~h}\left(\right.$ at $37^{\circ} \mathrm{C}, 5 \% \mathrm{CO}_{2}$ ), and the medium was replaced with MTT solution $(0.50 \mathrm{~g} / \mathrm{L})$, and cells were incubated for another $2 \mathrm{~h}$. The resulting blue formazan was solubilized in DMSO, and the absorbance at $560 \mathrm{~nm}$ was measured with a plate reader. The MTT reduction of untreated cell was set as $100 \%$, and that of treated cells was expressed as a percentage of untreated cells.

\section{Cell uptake}

4T1 mouse breast cancer cells were incubated with PAA-PNIPAm hydrogel capsules in a humidified atmosphere with $5 \% \mathrm{CO}_{2}$ at $37^{\circ} \mathrm{C}$. After incubation for $2 \mathrm{~h}$ to allow the $4 \mathrm{~T} 1$ cells to internalize the capsules, the noninternalized capsules were removed through washing three times with PBS solution. Cell nucleolus was stained by 2-(4-Amidinophenyl)-6-indolecarbamidine dihydrochloride (DAPI). Cells were observed using a laser confocal scanning microscope (LCSM, Zeiss LSM 710 , Germany) at an excitation wavelength of $543 \mathrm{~nm}$.

\section{Characterizations}

The morphology of particles and capsules was observed by transmission electron microscopy (TEM; JEOL TEM-1005) and scanning electron microscopy (SEM, HITACHI S-4800). The samples were dripped onto nitrocellulose-covered copper grid at room temperature without staining. The hydrodynamic diameter $\left(D_{h}\right)$ and size distribution of particles and capsules were measured by dynamic light scattering (DLS) using a Nano ZS system (Malvern Instruments Corporation, UK). Each sample was diluted to the appropriate concentration with water and repeatedly conducted for 3 times at $25^{\circ} \mathrm{C}$, obtaining the mean diameter. Zeta potential of the PAA-PNIPAm hydrogel capsules was determined by Zetaplus (Malvern Instruments Corporation, UK). All analyses were performed on samples adjusted with $0.01 \mathrm{M} \mathrm{NaCl}$ solution in order to maintain a constant ionic strength. Each measurement was triplicated and the result was the average of three runs.

\section{Results and discussion}

The strategy to prepare the PAA-PNIPAm hydrogel capsules is proposed in Fig. 1. The HPC-PAA template particles are prepared by the direct polymerization of AA monomers in HPC aqueous solution according to the method reported by $\mathrm{Hu}$ et al. [35]. Hydrogen bonding interaction between hydroxyl groups of HPC and carboxyl groups of PAA induces the formation of HPC-PAA particles in the aqueous solution. The size of the templates can be readily tuned from 100$1000 \mathrm{~nm}$ by varying the feed ratio of HPC to AA from 10:1 to $1: 2.5$ [33]. In this study, the [HPC]:[AA] was fixed at 1:1. After polymerization and cross-linking of monomer NIPAm on the surfaces of the HPC-PAA templates, cross-linked HPC-PAA-PNIPAm complex particles with core-shell structure were formed. It should be noted that increasing the $\mathrm{pH}$ of system could cause ionization of PAA as well as dissociation of hydrogen bonds and consequently the HPC component of the templates would re-dissolve in the solution and thus the templates would be broken. Hence, cross-linked PAA-PNIPAm hydrogel capsules could be obtained easily just after adjusting the $\mathrm{pH}$ of the solution to 8.0.

Figure 2 illustrates the TEM and SEM images of particles at each step. As shown in Fig. 2(a), HPCPAA template particles possessed morphology of round shape with an average diameter of about $135 \mathrm{~nm}$. After the polymerization and crosslinking of PNIPAm on the template surface at the second step, the size of the particles increased to about $230 \mathrm{~nm}$. Close observation of the particles were indicative of core-shell feature with a dark core and a dusky shell (Fig. 2(b)). After the removal of the template, the particles still kept the sphere morphology as seen in Fig. 2(d). By further TEM 


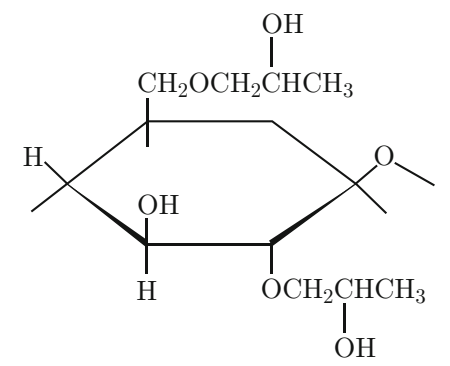<smiles>C=CC(=O)O</smiles>

AA

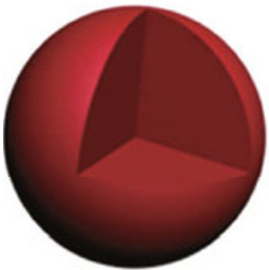

HPC-PAA particles
NIPAm+ crosslinker $\Rightarrow$

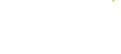

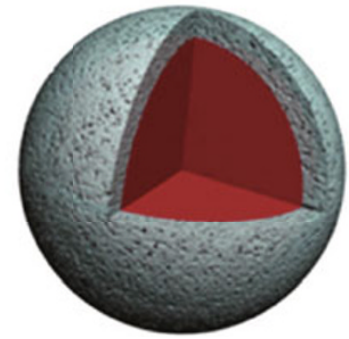

HPC-PAA-PNIPAm particles

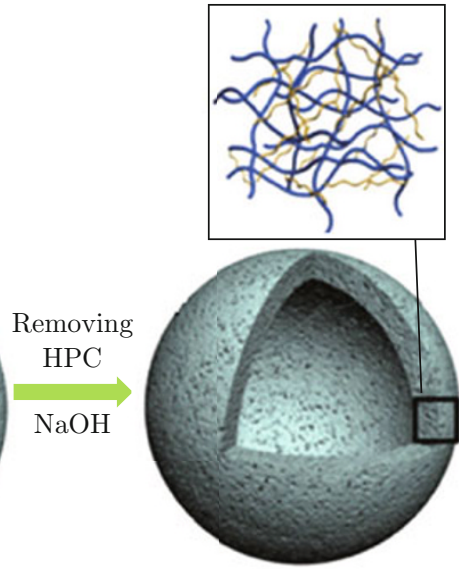

PAA-PNIPAm hydrogel capsules

Fig. 1 Schematic representation of the preparation of PAA-PNIPAm hydrogel capsules.
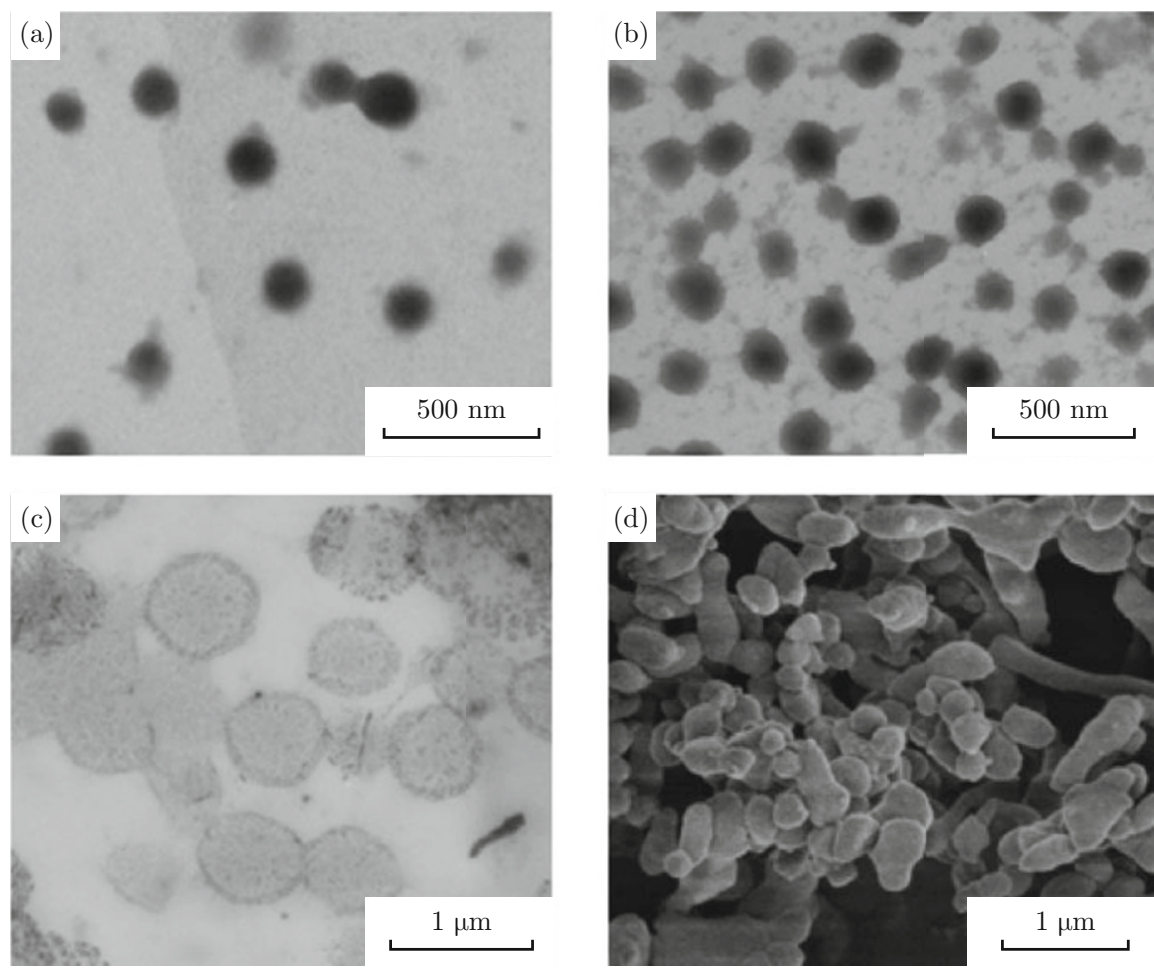

Fig. 2 TEM images of (a) HPC-PAA particles $(\mathrm{pH}=2.4)$; (b) HPC-PAA-PNIPAm composite particles $(\mathrm{pH}=2.4)$; and (c) PAA-PNIPAm hydrogel capsules $(\mathrm{pH}=8.0)$. (d) SEM image of PAA-PNIPAm hydrogel capsules after frozen drying treatment.

measurement, they were characterized by a thin shell and a fairly large inner cavity (Fig. 2(c)). The wall thickness is about $50 \pm 12.5 \mathrm{~nm}$ according to the TEM image. More interestingly, some mesopores penetrating from shell to the hollow interior of PAA-PNIPAm hydrogel capsules can be seen in the Fig. 2(c), which were probably the molecular imprint left by HPC after stripping from the HPC-PAA-PNIPAm particles. Compared to the HPC-PAA-PNIPAm particles, the size of
PAA-PNIPAm hydrogel capsules increased significantly to about $560 \mathrm{~nm}$, which maybe result from the intense swelling and the electrostatic repulsion generated by the complete ionization of PAA at $\mathrm{pH}=8.0$. Additionally, in virtue of removing the core, the restriction imposed by the hydrogen bonding between HPC and PAA was gradually released. This induced the particles to swell as well, accounting partially for their size increase. The size distributions of the particles in three steps 

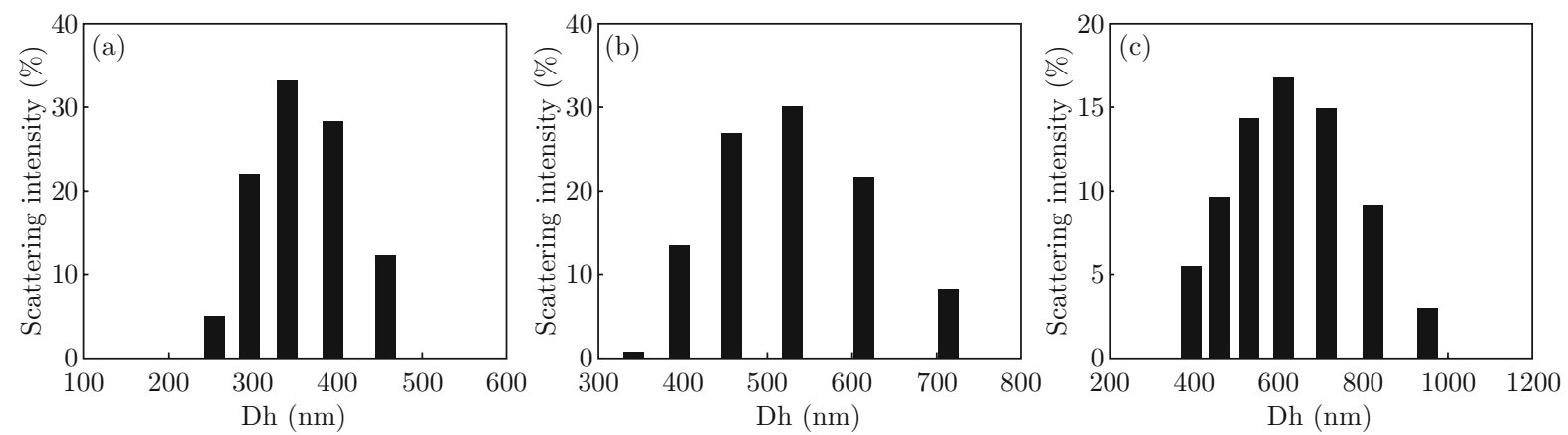

Fig. 3 The hydrodynamic diameter distribution of (a) HPC-PAA particles $(\mathrm{pH}=2.4)$; (b) HPC-PAA-PNIPAm composite particles $(\mathrm{pH}=2.4)$; and (c) PAA-PNIPAm hydrogel capsules $(\mathrm{pH}=8)$.

measured by DLS are shown in Fig. 3, which illustrates the agreeable trend of particles size with the TEM observations. The diameters from DLS measurements obviously greater than those from TEM measurements could be attributed to the stretching PNIPAm chains in the aqueous solution of $25^{\circ} \mathrm{C}$ and the shrinking PNIPAm chains under ultrahigh vacuum condition [36].

Considering the large space inside the capsules, the PAA-PNIPAm hydrogel capsules are expected to be drug carriers with superior loading capacity which is regarded as an important factor for the performance of drug carriers [37]. Here, a water-soluble antitumor agent, Doxorubicin hydrochloride (Dox), is selected as a model drug to evaluate its drug loading ability. The drug loading process proceeds easily by incubating the PAA-PNIPAm hydrogel capsules in Dox water solution at $37^{\circ} \mathrm{C}$ for $12 \mathrm{~h}$. The excessive Dox was removed by centrifugation, followed by repetitive washing with distilled water, leading to the drug-loaded hydrogel capsules. The UV-vis spectrum with the Dox characteristic absorption peak $495 \mathrm{~nm}$ (Fig. 4(a)) and LCSM section image of the Dox loaded PAA-PNIPAm hydrogel capsules (Fig. 4(a) inset) confirmed a successful entrapment of Dox into the capsules. Figure 4(b) depicted the loading capacity (LC) and loading efficiency (LE) of the PAA-PNIPAm hydrogel capsules corresponding to different feeding Dox concentrations at $\mathrm{pH}=7.0$. Along with the rise of the feeding drug concentration, increasing in the $\mathrm{LC}$ was observed. The maximum LC of $\sim 280 \%$ was exhibited at the feeding Dox concentration of $1.6 \mathrm{mg} / \mathrm{mL}$. Compared to analogous PAAPNIPAm polymer particles [34,38], the PAA-PNIPAm hydrogel capsules show higher loading capacity for Dox. The high loading of Dox in the PAA-PNIPAm hydrogel capsules may arise from the charge controlled permeability mechanism, i.e., negatively charged PAA in the capsules shell at neutral medium induces positively charged Dox to penetrate through the capsule shell and then deposit spontaneously into the interior of the capsules $[39,40]$. As previously reports, the incubation process usually exhibited lower loading capacity compared to the encapsulation method. However, the PAA-
PNIPAm hydrogel capsules herein still show high loading capacity using the incubation method, which suggests their convenient and low-cost loading procedure for drugs in future application.
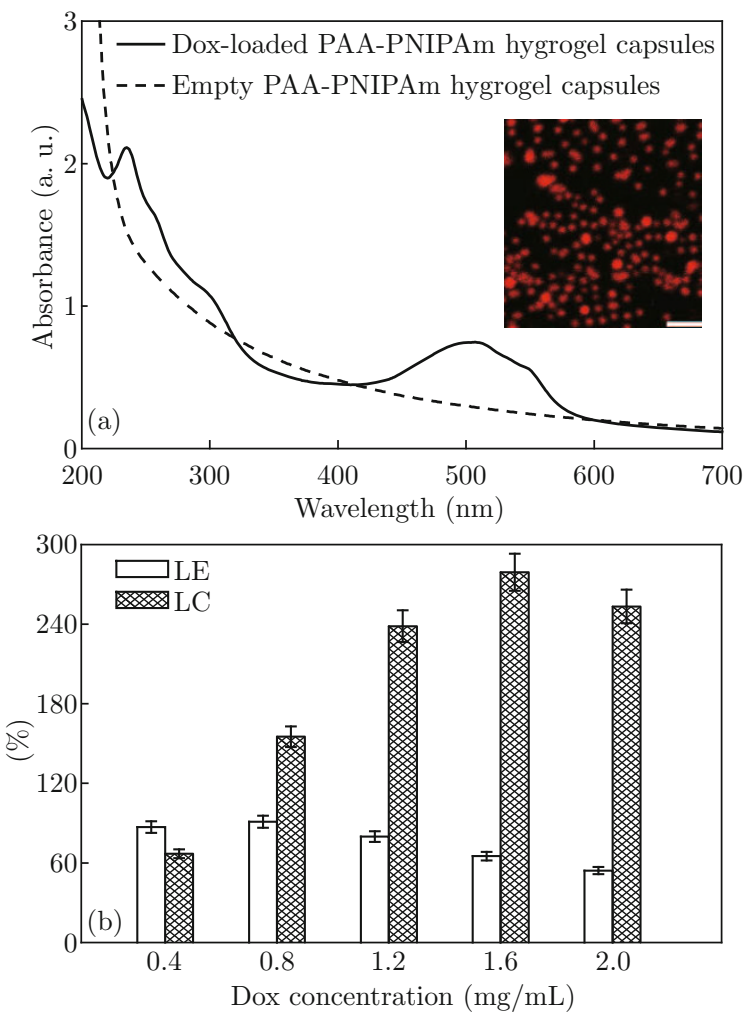

Fig. 4 (a) UV-vis spectra of Dox-loaded PAA-PNIPAm hydrogel capsules and empty PAA-PNIPAm hydrogel capsules; (inset) the LCSM image of the Dox-loaded PAAPNIPAm hydrogel capsules, the scale bar is $2 \mu \mathrm{m}$; (b) LC and LE of PAA-PNIPAm hydrogel capsules corresponding to different feeding Dox concentrations at $\mathrm{pH}=7.0$.

Upon changing the environmental conditions, the loaded drugs were released from the capsules in a controlled manner. Figure 5 described the release profiles of Dox from PAA-PNIPAm hydrogel capsules in different $\mathrm{pH}$ and temperature, showing a low-rate but sustained release characteristic compared with free Dox. 
For instance, at $\mathrm{pH}=7.4$ and the temperature of $37^{\circ} \mathrm{C}$, about $27 \%$ of the loaded Dox was released in the early $10 \mathrm{~h}$ and $33 \%$ of the total Dox was liberated continuously in the next $100 \mathrm{~h}$. This implied that the utilization of the PAA-PNIPAm hydrogel capsules as the Dox carrier was favorable for low-toxic and long-term therapy for cancer.
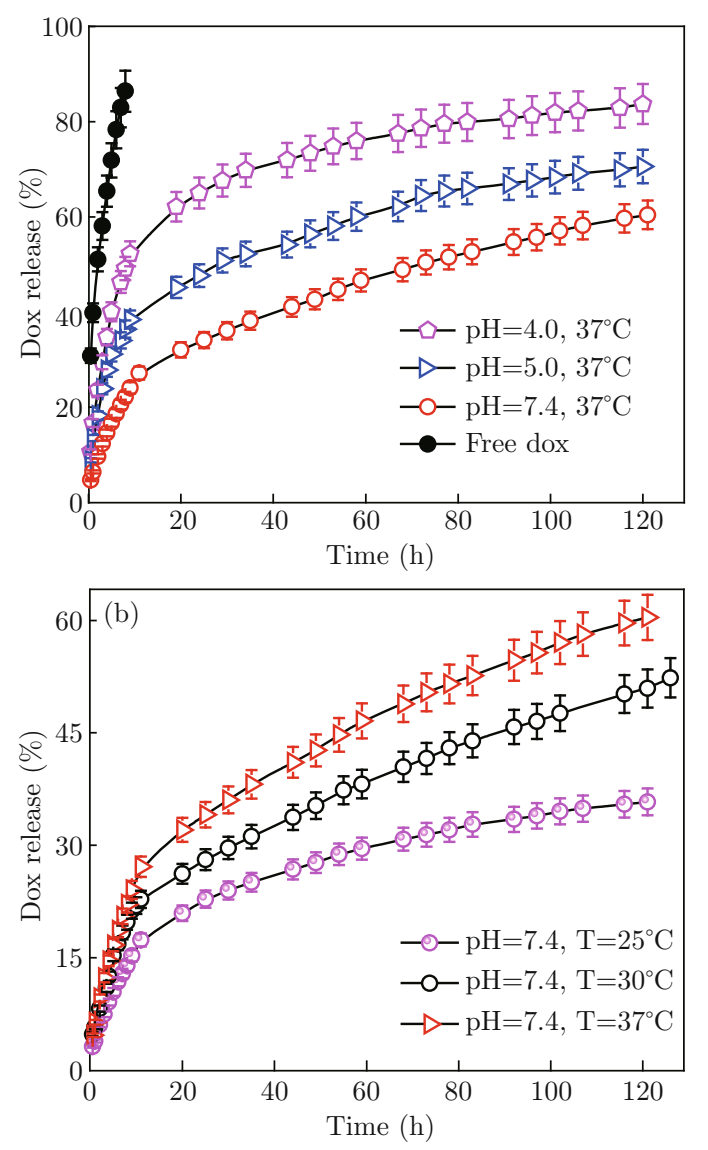

Fig. 5 Release profiles of Dox from the hydrogel capsules in PBS with different (a) $\mathrm{pH}$ and (b) temperatures.

Figure 5(a) revealed that the release behavior significantly correlates with the $\mathrm{pH}$ of release medium. The release rate of Dox from PAA-PNIPAm hydrogel capsules accelerates with the $\mathrm{pH}$ decreasing. This could be explained by the following two aspects. On one hand, the electrostatic interaction between PAA and Dox was actively responsive to the $\mathrm{pH}$ variation. At $\mathrm{pH}=7.4$, PAA chains and Dox molecules were fully ionized with opposite charges and the electrostatic interaction between them was too strong to make the entrapped Dox escape out rashly. As the $\mathrm{pH}$ drops down to 4.0, PAA chains were mainly protonated and the bonding force would be weakened greatly, boosting Dox to get off the cavity with ease. On the other hand, deswelling/swelling of the hydrogel capsules also had a certain effect on Dox release. In order to confirm the influence of $\mathrm{pH}$ on the size of hydrogel capsules, PAA-PNIPAm hydrogel capsules were incubated in a set of buffer solution with different $\mathrm{pH}$ values $(\mathrm{pH}$ $=2.0,3.0,4.0,5.0,6.0,7.0,8.0,9.0,10.0$ ) for $24 \mathrm{~h}$. The size and zeta potential of samples at each $\mathrm{pH}$ were shown in Fig. 6. It could be found that as the $\mathrm{pH}$ increasing from 2.0 to 6.0 , a remarkable increase in the size of PAA-PNIPAm hydrogel capsules was observed from $365 \mathrm{~nm}$ to $578.4 \mathrm{~nm}$. This could be explained that the ionization degree of PAA chains gradually enlarges and the electrostatic repulsion between $\mathrm{COO}^{-}$groups of PAA causes the whole sphere to be swelling increasingly. Particularly, in the $\mathrm{pH}$ range from 4.0 to 6.0 , the size showed a dramatic increase possibly being associated with the $p K_{a}$ of 4.75 for PAA. When the $\mathrm{pH}$ was beyond 6.0 , there was little change in the size due to the complete deprotonation of PAA. Meanwhile, the zeta potential also revealed a similar variety trend. The gradual shrinking of the capsules could undoubtedly narrow their inner volume and force more entrapped Dox to release out of the cavity. This $\mathrm{pH}-$ dependent releasing behavior was favorable for the antitumor drug delivery system, since tumor cells were often at a lower $\mathrm{pH}$ level of 5.7-7.8 [41], which would induce a faster drug release in the diseased cells than in the normal cells.

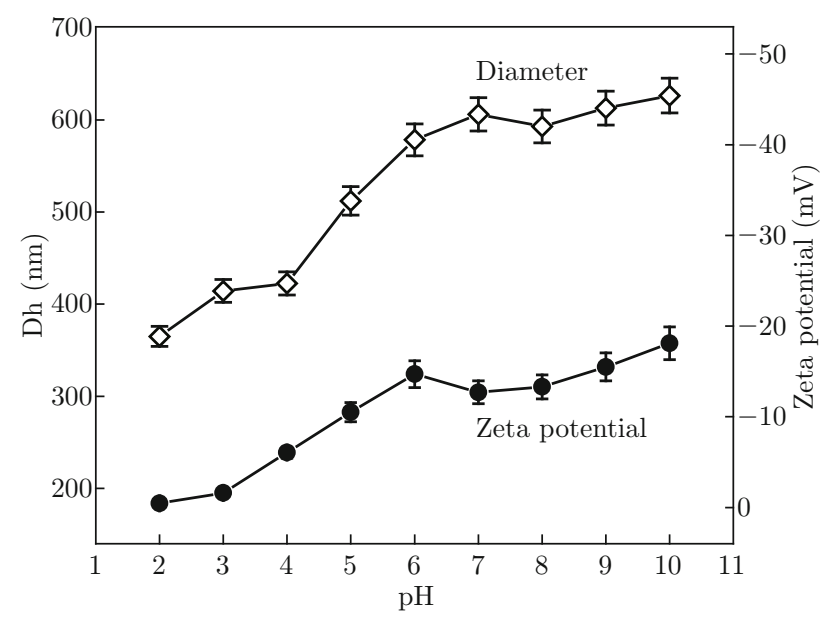

Fig. 6 Size and zeta potential of PAA-PNIPAm hydrogel capsules at different $\mathrm{pH}$.

It is noteworthy that PNIPAm belongs to thermoresponsive polymers, so the PAA-PNIPAm hydrogel capsules serving as drug carriers are expected to exhibit a thermo controlled-released character. In order to verify this inference, the Dox-loaded hydrogel capsules were dialyzed in PBS $(\mathrm{pH}=7.4)$ at different temperatures. The release profiles at different temperatures depicted in Fig. 5(b). Based on the previous analysis, it was concluded that the obtained PAA-PNIPAm hydrogel capsules, of which the drug release was dualresponsive to both temperature and $\mathrm{pH}$, and could be able to intelligently distinguish between normal and pathological tissues, achieving better targeting efficiency 

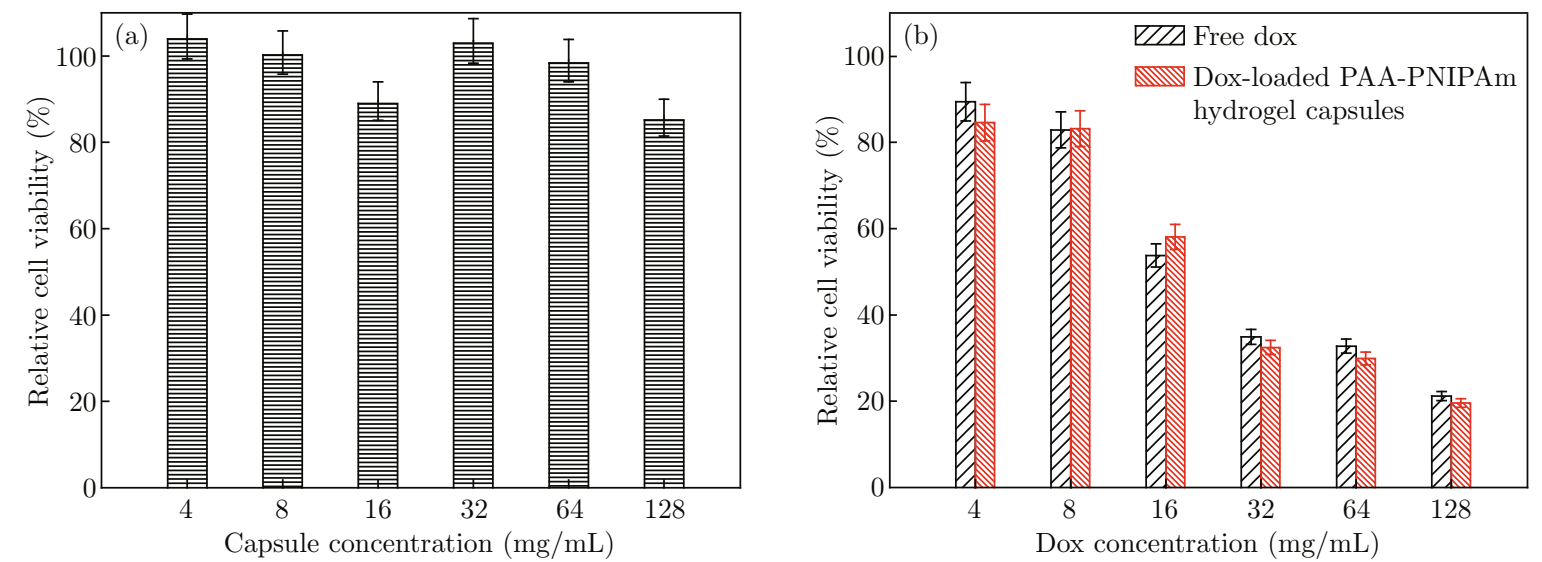

Fig. 7 In vitro cytotoxicity of (a) empty PAA-PNIPAm hydrogel capsules; and (b) Dox-loaded PAA-PNIPAm hydrogel capsules, free Dox against LoVo cell line at normal concentration.
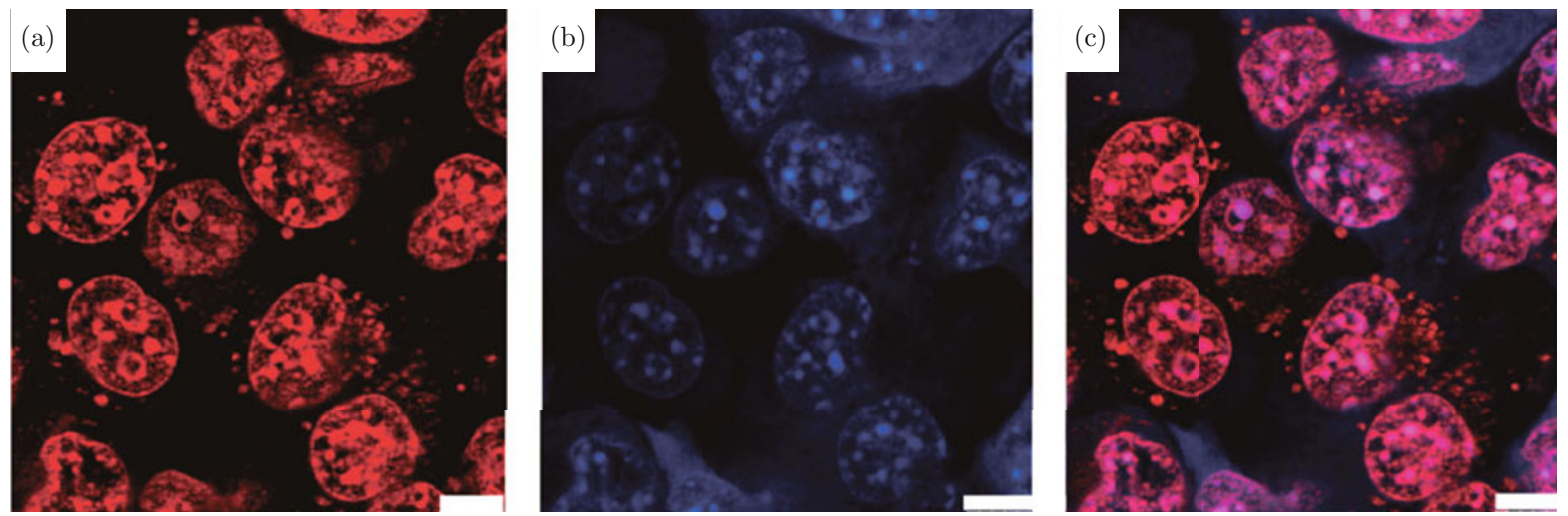

Fig. 8 LCSM images of 4T1 cells incubated with Dox-loaded PAA-PNIPAm hydrogel capsules for 2 h: red from Dox (a); blue from nuclei (b); and overlaid (c). The scale bar is $10 \mu \mathrm{m}$.

and treatment efficacy, and foreseeing an application to the drug controlled-released system.

To investigate the potential toxicity of the PAAPNIPAm hydrogel capsules and the pharmacological activity of Dox released from the hydrogel capsules, empty and Dox-loaded PAA-PNIPAm hydrogel capsules solution were incubated with human intestine cancer cell line LoVo cells to examine their effect on cell viability with a positive control of free Dox. The MTT assay (Fig. 7(a)) showed that, even at high concentrations of $128 \mu \mathrm{g} / \mathrm{mL}$, PAA-PNIPAm hydrogel capsules still have no significant cytotoxicity. In vitro cytotoxicity of Dox-loaded hydrogel capsules and free Dox against LoVo cell were exhibited in Fig. 7(b). It could be observed that the cytotoxicity of Dox-loaded hydrogel capsules was almost equivalent to that of free Dox, implying that the drug efficacy released from the hydrogel capsules was scarcely influenced by the process of drug loading, which was in agreement with our previous work $[32,34]$. LCSM characterization was used to further examine cellular uptakes of PAA-PNIPAm hydrogel capsules. Figure 8 showed the section images of $4 \mathrm{~T} 1$ mouse breast cancer cells after incubation with the Dox-loaded hydrogel capsules at $37^{\circ} \mathrm{C}$ for $2 \mathrm{~h}$. As shown in Fig. 8 (a)-(c), the Dox-loaded hydrogel capsules with red fluorescence arising from Dox were observed to mainly distribute in the cytoplasm of cells, indicating that the hydrogel capsules could overcome cellular barriers to enter the intracellular region, although it carried negative surface charges, which was consistent with the results reported by Savic et al. [42]. Moreover, the red fluorescence in the nuclei came from the Dox migrating and accumulating in the nuclei after releasing from the hydrogel capsules localized in the cytoplasm. These results firmly confirmed that the PAA-PNIPAm hydrogel capsules as a drug carrier had an excellent biosecurity and a high pharmacological activity.

\section{Conclusions}

We have demonstrated the convenient preparation of PAA-PNIPAm hydrogel capsules in this work, which were fabricated by a templated strategy in aqueous solution. Hydrophilic antitumor drug Dox was successfully entrapped in these hydrogel capsules based on charge controlled permeability mechanism, leading to a new high loading capacity of $\sim 280 \%$ to the weight of the 
carriers. More encouragingly, the release of drug from the PAA-PNIPAm hydrogel capsules exhibited a slowrate but sustainable feature, and behaved the thermo and $\mathrm{pH}$ dual-responsivity. In vitro cytotoxicity assay indicated that the Dox-loaded PAA-PNIPAm hydrogel capsules have high antitumor activity. Considering the simple and mild preparation procedure, high drug loading capacity as well as the desired dual-responsive controlled release property, the PAA-PNIPAm hydrogel capsules may serve as a promising candidate for intelligent drug delivery system.

\section{Acknowledgements}

This work is financially supported by the National Natural Science Foundation of China (Grant No. 31100427, No. 81101751) and the Jiangsu Province Natural Science Foundation (BK20131071).

\section{References}

[1] K. Kataoka, A. Harada and Y. Nagasaki, "Block copolymer micelles for drug delivery: design, characterization and biological significance", Adv. Drug Del. Rev. 47(1), 113-131 (2001). http://dx.doi.org/10. 1016/S0169-409X (00) 00124-1

[2] N. Kolishetti, S. Dhar, P. M. Valencia, L. Q. Lin, R. Karnik, S. J. Lippard, R. Langer and O. C. Farokhzad, "Engineering of self-assembled nanoparticle platform for precisely controlled combination drug therapy", Proc. Natl. Acad. Sci. 107(42), 17939-17944 (2010). http://dx.doi.org/10.1073/pnas.1011368107

[3] Y. Chen, X. Zheng, X. Wang, C. Wang, Y. Ding and X. Jiang, "Near-Infrared emitting gold clusterpoly (acrylic acid) hybrid nanogels", ACS Macro Lett. 3(1), 74-76 (2014). http://dx.doi.org/10. $1021 / \mathrm{mz} 4005748$

[4] R. C. Nagarwal, S. Kant, P. Singh, P. Maiti and J. Pandit, "Polymeric nanoparticulate system: a potential approach for ocular drug delivery", J. ControlledRelease 136(1), 2-13 (2009).http://dx. doi.org/10. $1016 / j \cdot j$ conrel . 2008.12.018

[5] J. Panyam and V. Labhasetwar, "Biodegradable nanoparticles for drug and gene delivery to cells and tissue", Adv. Drug Del. Rev. 55(3), 329-347 (2003). http://dx.doi.org/10.1016/ S0169-409X (02) 00228-4

[6] T. R. Hoare and D. S. Kohane, "Hydrogels in drug delivery: progress and challenges", Polymer 49(8), 1993-2007 (2008). http://dx.doi.org/10. $1016 / j$. polymer. 2008.01.027

[7] J. Kost and R. Langer, "Responsive polymeric delivery systems", Adv. Drug Del. Rev. 46(13), 125-148 (2001). http://dx.doi.org/10.1016/ S0169-409X (00) 00136-8

[8] J. Della Rocca, D. Liu and W. Lin, "Nanoscale metalorganic frameworks for biomedical imaging and drug delivery", Acc. Chem. Res. 44(10), 957-968 (2011). http://dx.doi.org/10.1021/ar200028a

[9] Y. Chen, P. A. Wilbon, J. Zhou, M. Nagarkatti, C. Wang, F. Chu and C. Tang, "Multifunctional selffluorescent polymer nanogels for label-free imaging and drug delivery", Chem. Commun. 49(3), 297-299(2013). http://dx.doi.org/10.1039/C2CC37386F

[10] J. Wang, K. Yao, C. Wang, C. Tang and X. Jiang, "Synthesis and drug delivery of novel amphiphilic block copolymers containing hydrophobic dehydroabietic moiety", J. Mater. Chem. B 1(17), 2324-2332 (2013). http://dx.doi.org/10.1039/C3TB20100G

[11] G. Stoychev, N. Puretskiy and L. Ionov, "Selffolding all-polymer thermoresponsive microcapsules", Soft Matter 7(7), 3277-3279 (2011). http://dx.doi. org/10.1039/C1SM05109A

[12] S. Sivakumar, V. Bansal, C. Cortez, S. F. Chong, A. N. Zelikin and F. Caruso, "Degradable, surfactant-free, monodisperse polymer-encapsulated emulsions as anticancer drug carriers", Adv. Mater. 21(18), 1820-1824 (2009). http://dx.doi.org/10. 1002/adma. 200802475.

[13] B. Städler, A. D. Price, R. Chandrawati, L. HostaRigau, A. N. Zelikin and F. Caruso, "Polymer hydrogel capsules: en route toward synthetic cellular systems", Nanoscale 1, 68-73 (2009). http://dx.doi. org/10.1039/B9NR00143C

[14] G. K. Such, A. P. Johnston and F. Caruso, "Engineered hydrogen-bonded polymer multilayers: from assembly to biomedical applications", Chem. Soc. Rev. 40(1), 19-29 (2011). http://dx.doi.org/10. 1039/COCS00001A

[15] A. G. Skirtach, A. M. Yashchenok and H. Möhwald, "Encapsulation, release and applications of LbL polyelectrolyte multilayer capsules", Chem. Commun. 47(48), 12736-12746 (2011). http://dx.doi.org/10. 1039/C1CC13453A

[16] L. Loretta, P. Rivera-Gil, A. Z. Abbasi, M. Ochs, C. Ganas, I. Zins, C. Sönnichsen and W. J. Parak, "LbL multilayer capsules: recent progress and future outlook for their use in life sciences", Nanoscale 2(4), 458-467 (2010). http://dx.doi.org/10.1039/B9NR00341J

[17] G. Ibarz, L. Dähne, E. Donath and H. Moehwald, "Smart micro-and nanocontainers for storage, transport, and release", Adv. Mater. 13(17), 1324-1327 (2001). http://dx.doi.org/10.1002/ 1521-4095 (200109) 13: 17

[18] G. B. Sukhorukov, A. A. Antipov, A. Voigt, E. Donath and H. Möhwald, "pH-Controlled macromolecule encapsulation in and release from polyelectrolyte multilayer nanocapsules", Macromol. Rapid Commun. 22(1), 44-46 (2001). http://dx.doi.org/ 10.1002/1521-3927

[19] A. A. Antipov, G. B. Sukhorukov and H. Möhwald, "Influence of the ionic strength on the polyelectrolyte multilayers' permeability", Langmuir 19(6), 2444-2448 (2003). http://dx.doi.org/10.1021/la026101n

[20] R. Chandrawati, B. Städler, A. Postma, L. A. Connal, S.-F. Chong, A. N. Zelikin and F. Caruso, 
"Cholesterol-mediated anchoring of enzyme-loaded liposomes within disulfide-stabilized polymer carrier capsules", Biomaterials 30(30), 5988-5998 (2009). http://dx.doi.org/10.1016/j.biomaterials. 2009 . 07.040

[21] Y. Yan, A. P. Johnston, S. J. Dodds, M. M. Kamphuis, C. Ferguson, R. G. Parton, E. C. Nice, J. K. Heath and F. Caruso, "Uptake and intracellular fate of disulfide-bonded polymer hydrogel capsules for doxorubicin delivery to colorectal cancer cells", ACS Nano 4(5), 2928-2936 (2010). http://dx.doi.org/10.1021/ nn100173h

[22] S. F. Chong, R. Chandrawati, B. Städler, J. Park, J. Cho, Y. Wang, Z. Jia, V. Bulmus, T. P. Davis and A. N. Zelikin, "Stabilization of polymerhydrogel capsules via thiol-disulfide exchange", Small $5(22)$, 2601-2610 (2009). http://dx.doi.org/10. $1002 / \mathrm{smll} .200900906$

[23] M. Motornov, H. Royter, R. Lupitskyy, Y. Roiter and S. Minko, "Stimuli-esponsive hydrogel hollow capsules by material efficient and robust crosslinking-precipitation synthesis revisited", Langmuir 27(24), 15305-15311 (2011). http://dx.doi.org/10. 1021/la204286a

[24] B. Städler, A. D. Price and A. N. Zelikin, "A critical look at multilayered polymer capsules in biomedicine: drug carriers, artificial organelles, and cell mimics", Adv. Funct. Mater. 21(1), 14-28 (2011). http://dx. doi.org/10.1002/adfm. 201001676

[25] S. De Koker, L. J. De Cock, P. Rivera-Gil, W. J. Parak, R. Auzély Velty, C. Vervaet, J. P. Remon, J. Grooten and B. G. De Geest, "Polymeric multilayer capsules delivering biotherapeutics", Adv. Drug Del. Rev. 63(9), 748-761 (2011). http://dx.doi.org/10. 1016/j . addr. 2011.03.014

[26] T. Chen, B. Du and Z. Fan, "Facile fabrication of polymer nanocapsules with cross-linked qrganic-inorganic hybrid walls", Langmuir 28(30), 11225-11231 (2012). http://dx.doi.org/10.1021/la301872q

[27] M. Motornov, Y. Roiter, I. Tokarev and S. Minko, "Stimuli-responsive nanoparticles, nanogels and capsules for integrated multifunctional intelligent systems", Prog. in Polym. Sci. 35(12), 174-211 (2010). http://dx.doi.org/10.1016/j. progpolymsci.2009.10.004

[28] Y. Zhao, H. C. Shum, L. L. Adams, B. Sun, C. Holtze, Z. Gu and D. A. Weitz, "Enhanced encapsulation of actives in self-sealing microcapsules by precipitation in capsule shells", Langmuir 27(23), 13988-13991 (2011). http://dx.doi.org/10.1021/la2034774

[29] N. Elsner, V. Kozlovskaya, S. A. Sukhishvili and A. Fery, "pH-Triggered softening of crosslinked hydrogenbonded capsules", Soft Matter 2(11), 966-972 (2006). http://dx.doi.org/10.1039/B608317 J

[30] V. Kozlovskaya and S. A. Sukhishvili, "Amphoteric hydrogel capsules: multiple encapsulation and release routes", Macromolecules 39(18), 6191-6199 (2006). http://dx.doi.org/10.1021/ma0613640

[31] V. Kozlovskaya, E. Kharlampieva, M. L. Mansfield and S. A. Sukhishvili, "Poly (methacrylic acid) hydrogel films and capsules: response to $\mathrm{pH}$ and ionic strength, and encapsulation of macromolecules", Chem. Mater. 18(2), 328-336 (2006). http://dx.doi.org/10.1021/ cm0517364

[32] Y. Chen, X. Zheng, H. Qian, Z. Mao, D. Ding and $\mathrm{X}$. Jiang, "Hollow core-porous shell structure poly (acrylic acid) nanogels with a superhigh capacity of drug loading", ACS Appl. Mater. Inter. 2(12), 35323538 (2010). http://dx.doi.org/10.1021/am100709d

[33] Y. Chen, D. Ding, Z. Mao, Y. He, Y. Hu, W. Wu and X. Jiang, "Synthesis of hydroxypropylcellulose-poly (acrylic acid) particles with semi-interpenetrating polymer network structure", Biomacromolecules 9(10), 2609-2614 (2008). http://dx.doi.org/10. 1021/bm800484e

[34] Y. Chen, J. Nan, C. Wang and F. Chu, "Hollow poly (N-isopropylacrylamide)-co-poly (acrylic acid) microgels with high loading capacity for drugs", J. Appl. Polym. Sci. 124(6), 4678-4685 (2012). http://dx.doi. org/10.1002/app.35515

[35] X. Lu, Z. Hu and J. Schwartz, "Phase transition behavior of hydroxypropylcellulose under interpolymer complexation with poly (acrylic acid)", Macromolecules 35(24), 9164-9168 (2002). http://dx.doi. org/10.1021/ma0208842

[36] H. Gao, W. Yang, K. Min, L. Zha, C. Wang and $\mathrm{S} . \mathrm{Fu}$, "Thermosensitive poly (N-isopropylacrylamide) nanocapsules with controlled permeability", Polymer 46(4), 1087-1093 (2005). http://dx.doi.org/10. $1016 / j$. polymer . 2004 . 11.078

[37] K. S. Soppimath, T. M. Aminabhavi, A. R. Kulkarni and W. E. Rudzinski, "Biodegradable polymeric nanoparticles as drug delivery devices", J. Controlled Release 70(1-2), 1-20 (2001). http://dx.doi.org/10. 1016/S0168-3659(00)00339-4

[38] G. Li, S. Song, L. Guo and S. Ma, "Self-assembly of thermo-and pH-responsive poly (acrylic acid)-b-poly (N-isopropylacrylamide) micelles for drug delivery", J. Polym. Sci., Part A: Polym. Chem. 46(15), 5028-5035 (2008). http://dx.doi.org/10.1002/pola. 22831

[39] W. Tong, W. Dong, C. Gao and H. Möhwald, "Chargecontrolled permeability of polyelectrolyte microcapsules", J. Phys. Chem. B 109(27), 13159-13165 (2005). http://dx.doi.org/10.1021/jp0511092

[40] A. A. Antipov, G. B. Sukhorukov, S. Leporatti, I. L. Radtchenko, E. Donath and H. Möhwald, "Polyelectrolyte multilayer capsule permeability control", Colloids Surf. Physicochem. Eng. Aspects 198200, 535-541 (2002). http://dx.doi.org/10.1016/ S0927-7757(01) 00956-6

[41] G. R. Martin and R. K. Jain, "Noninvasive measurement of interstitial $\mathrm{pH}$ profiles in normal and neoplastic tissue using fluorescence ratio imaging microscopy", Cancer Res. 54, 56705674 (1994). http://cancerres.aacrjournals.org/ content/54/21/5670.full.pdf+html

[42] R. Savic, L. Luo, A. Eisenberg and D. Maysinger, Micellar Nanocontainers "Distribute to defined cytoplasmic organelles", Science 300(5619), 615-618 (2003). http://dx.doi.org/10.1126/science. 1078192 